\title{
Effects of Injection Enhancement Carrageenan, Sea-salt, and Potassium Lactate on Beef longissimus lumborum Muscle Sensorial Characteristics and Color Stability
}

Nakia Lee, Vijendra Sharma, Rakesh Singh and Anand Mohan*

Department of Food Science and Technology, University of Georgia, Athens, GA 30606, USA

\begin{abstract}
To determine the effects of injection ingredients and USDA quality grade response on meat color stability, beef strip loins representing two quality grades (USDA Choice and Select) were enhanced with either 0.25 CG [0.25\% kappa-carrageenan $+1 \%$ sea salt $+0.3 \%$ sodium tripolyphosphate]; 0.50 CG $[0.50 \%$ kappa-carrageenan $+1 \%$ sea salt $+0.3 \%$ sodium tripolyphosphate; or $2.5 \mathrm{KL}$ [2.5\% potassium lactate $+1 \%$ sea salt $+0.3 \%$ sodium tripolyphosphate]; or NEC = non-enhanced control. Changes in surface color, visual appearance, discoloration, and metmyoglobin formation during a $7 \mathrm{~d}$ retail display at $2^{\circ} \mathrm{C}$ were evaluated. Enhancement with $0.50 \mathrm{CG}$ and $2.5 \mathrm{KL}$ affected $(\mathrm{P}<0.05)$ display color properties and metmyoglobin reduction. Enhanced $\mathrm{Choice}$ steaks outperformed Select steaks in color stability and palatability characteristics and enhancement with $2.5 \mathrm{KL}$ induced red color darkening in enhanced steaks. This study shows that kappa-carrageenan will effectively enhance color stability, improve expected eating quality, and minimize discoloration during retail display and storage.
\end{abstract}

Keyword: Beef; Meat color; Injection-enhancement; Carrageenan; Lactate; Sea-salt

\section{Introduction}

Meat color is an important quality attribute that consumers associate with freshness of retail products. Discoloration due to inconsistencies in quality and ineffective control of other influences on meat color cause billions of retail sales dollars lost each year. Discoloration alone leads to price discounts for about $15 \%$ of retail beef, for annual revenue losses of $\$ 1$ billion. Meeting consumer expectations for a consistent, high-quality meat product has been a challenge for the US beef industry. Consumers consider color and tenderness the most important purchasing criteria, so maintaining meat color during retail cold chain management requires a delicate balance of biochemical factors affecting meat color during retail sales.

Quality grades are a subjective quality assessment used in the beef industry to describe the expected eating quality of beef. The United States Department Agriculture (USDA) uses a measurable quality assessment criteria to reflect differences in expected eating quality among slaughter cattle's physiological maturity and marbling (the amount and distribution of intramuscular fat) to determine the USDA Quality Grades [1]. Changes in the skeletal characteristics with animal age is critical, however, differences in quality grades of beef do not follow a definitive pattern of meat quality degradation and differences in expected eating quality. Differences in quality grades of beef with inherent differences in intrinsic quality traits may affect meat color stability and other sensory characteristics.

Enhancement is the process of adding non-meat ingredients to fresh meats to improve the eating quality of the final processed product. In most cases, during enhancement, beef is injected with a variety of non-meat ingredients intended to enhance its texture, flavor, and consistency. The ingredients typically include salt, phosphate, antimicrobials, seasoning, and flavorings. Injecting meat with nonmeat ingredients has been shown to improve beef color shelf-life [25], decrease purge loss and improve juiciness, flavor, taste, and overall tenderness [6-9].

Several researchers have reported that beef steaks with injected with salt, sodium trypolyphosphate, and potassium lactate were more tender, juicy, and developed positive flavor notes than non-enhanced steaks. Applying carrageenan increases cook-yield and sliceability in roasted turkey breasts [10], improves water holding capacity in breakfast sausages [11], and increases cook-yield and bind strength of low-fat sausages [12]. Carrageenans are naturally-occurring hydrocolloids used primarily to enhance functional properties of meat. As a non-meat ingredient, carrageenan can increase processing yield and improve product functional properties.

Hsu and Chung reported that kappa-carrageenan ( $\kappa$-Carr) improved the textural profile of low fat meat balls. In a similar study, $\kappa$-Carr improved water retention in sausage [13], enhanced sensory properties of ham [14], and textural properties of beef patties [15-17]. Among several hydrocolloids used in meat, $\kappa$-Carr is the most widely used ingredient in the food industry in a broad range of products including canned meats, pet foods, and comminuted meat products [18].

Further research would help explain the biochemical interaction of meat proteins, like myoglobin with $\kappa$-Carr, as a way to achieve desirable quality characteristics in processed beef products. Therefore, the objective of this study was to evaluate the effects of injectionenhancement with $\kappa$-Carr, sodium tripolyphosphate, potassium lactate, and sea salt on beef strip loin muscle (USDA Choice and Select grades) color stability during retail display and storage.

\section{Materials and Methods}

\section{Raw materials}

Forty-eight boneless, beef strip loins (Institutional Meat Purchase

*Corresonding author: Anand Mohan, Department of Food Science and Technology, University of Georgia, Athens, GA 30606, USA, Tel: +1 706542 6673; Fax: +1 706542 9066; E-mail: anandm@uga.edu

Received November 05, 2014; Accepted November 18, 2014; Published December 02, 2014

Citation: Lee N, Sharma V, Singh R, Mohan A (2014) Effects of Injection Enhancement Carrageenan, Sea-salt, and Potassium Lactate on Beef longissimus lumborum Muscle Sensorial Characteristics and Color Stability. J Food Process Technol 5: 400. doi:10.4172/2157-7110.1000400

Copyright: (c) 2014 Lee N, et al. This is an open-access article distributed under the terms of the Creative Commons Attribution License, which permits unrestricted use, distribution, and reproduction in any medium, provided the original author and source are credited. 
Citation: Lee N, Sharma V, Singh R, Mohan A (2014) Effects of Injection Enhancement Carrageenan, Sea-salt, and Potassium Lactate on Beef longissimus lumborum Muscle Sensorial Characteristics and Color Stability. J Food Process Technol 5: 400. doi:10.4172/2157-7110.1000400

Page 2 of 9

Specification \# 180) representing two quality grades [n $=24$ USDA Select, and $\mathrm{n}=24$ USDA Choice) from A-maturity (9-30 months old cattle) carcasses were obtained from a local commercial abattoir at 10 -d postmortem. US Department of Agriculture (USDA) uses quality grades for determining the expected eating characteristics (e.g. tenderness, juiciness, and flavor) by evaluating the amount of marbling (Prime $=$ abundant to moderate; Choice $=$ Modest to small; and Select $=$ Slight to Traces $)$ present is a particular carcass maturity group $(\mathrm{A}=$ 9-30 months; $\mathrm{B}=30-42$ months; $\mathrm{C}=42-72$ months; $\mathrm{D}=72-96$ months; and $\mathrm{E}=$ more than 96 months). A marbling score is used by the USDA to determine the quality grades for beef.

\section{Chemicals}

Sodium tripolyphosphate (STPP) was obtained from Sigma Chem. Co. (St. Louis, MO, USA). $\kappa$-Carrarrageenan ( $\kappa$-Carr) was obtained from (S-100Fi, Ingredient Solutions Inc., Waldo, ME). Potassium lactate (KL) was obtained from PURAC America, Inc. (PURASAL HiPure $\mathrm{P}, 60 \%$ potassium lactate $/ 40 \%$ water; Lincolnshire, IL, USA). Sea-salt (SS), a low sodium salt (Salona ${ }^{\mathrm{mm}}$, ICL Performance Products LP, St. Louis, MO), was used to reduce total sodium content in the finished product. Distilled water was used throughout the preparation of all treatment solutions.

\section{Sampling and injection enhancement}

Forty-eight beef strip loins (IMPS 180), representing two quality grades (24 U.S. Choice loins and 24 U.S. Select loins), were obtained from a commercial beef purveyor. Six loins of each grade were cut into halves and randomly assigned to four injection enhancement treatments. The anterior cut portion served as non-enhanced (untreated) control (NEC), and the posterior half portion was weighed (raw product weight) and injection enhanced (Schroder Injector/ marinator, model N50, Wolf-Tec Inc., Kingston, NY) with either 0.25 CG $[0.25 \%$ к-Carr $+1 \%$ sea salt $(\mathrm{SS})+0.3 \%$ sodium tripolyphosphate (STPP)]; 0.50 CG [0.50\% к-Carr + 1\% SS + 0.3\% STPP; or $2.5 \mathrm{KL}[2.5 \%$ potassium lactate $(\mathrm{KL})+1 \% \mathrm{SS}+0.3 \% \mathrm{STPP}]$. Injected cuts were allowed to drain and were re-injected to targeted percentages $(110 \pm$ $2 \%$ of the green weight). Following a 2 min rest period, injected loins were reweighed to ensure brine was assimilated to achieve minimum $110 \%$ of the original weight. All $\kappa$-Carr, phosphate, sea-salt, and/or lactate injection solutions were formulated to yield enhanced final product with $0.25 \%$ к-Carr, $0.3 \%$ STPP, $1.0 \%$ SS, and $2.5 \% \mathrm{KL}$.

\section{Packaging and display}

Two hours after enhancement, loins were cut into six $2.54 \mathrm{~cm}$ thick steaks. Three steaks were used for Metmyoglobin Reducing Activity (MRA) measurements: one for visual color, one for instrumental color measurement, and one for $\mathrm{pH}$ and proximate analysis. Steaks for the color measurements (visual and instrumental) were overwrapped with polyvinyl chloride film (PVC; MAPACL, 21,700 cc O $/ \mathrm{m}^{2} / 24 \mathrm{hr}$ at standard temperature $\left(23^{\circ} \mathrm{C}\right)$ and pressure $(760 \mathrm{~mm} \mathrm{Hg})$, Borden Packaging and Industrial Products, North Andover, MA, USA) on foam trays (polystyrene foam; 17S; McCune Paper Company, Salina, KS, USA) with a Dri-Loc soaker pad (AC-50; Sealed Air Corp, Duncan, SC, USA). Steaks were displayed at $2^{\circ} \mathrm{C} \pm 1$ for 7 -d under $2150 \pm 50$ lux of continuous fluorescent lighting (bulb F32T8/ADV830, $3000 \mathrm{~K}$, CRI = 86; Phillips, Bloomfield, NJ, USA) in an open-front refrigerated display case (Model: Hussmann M3X, self-contained, multi-deck, Supermarket Equipment Sales, Inc., Rutledge, GA, USA). Visual and instrumental color measurements were recorded at predetermined time intervals for $0,1,2,3,4,5,6$ and 7-d of retail display. Packages were rotated twice daily to obtain a random sample placement and to minimize display case location effects.

\section{pH measurement}

The $\mathrm{pH}$ measurements were recorded for all meat portions before and after injection using a pierce-probe $\mathrm{pH}$ meter (Model $\mathrm{pH}$ 77-SS, metal probe, IQ Scientific, HACH, Loveland, CO, USA). The $\mathrm{pH}$ was measured in triplicate at three different locations on the same loin and averaged for statistical analysis (Table 1).

\section{Instrumental color measurement}

Instrumental color measurements were recorded on each steak through the packaging film at three different locations (randomly selected) and averaged for statistical analysis. Color measurements were recorded using HunterLab MiniScan ${ }^{\text {tix }}$ EZ Plus Spectrophotometer 45/0 LAV, 2.54-cm-diameter aperture, $10^{\circ}$ standard observer (Hunter Associates Laboratory, Inc., Reston, VA, USA). Values for CIE $L^{*}, a^{*}$, and $b^{*}$ (Illuminant A) were collected, and Hue Angle (HA) $\left(\tan ^{-1} b^{*} / a^{*}\right)$ and Saturation Index (SI) or chroma $\left[\left(a^{\star 2}+b^{\star 2}\right)^{1 / 2}\right]$ were calculated from instrumental measurements according to American Meat Science Association, Meat Color Guidelines [19]. The spectrophotometer was standardized against a black and white glass tile at least once every day before taking the color measurements.

\section{Metmyoglobin reducing activity}

Metmyoglobin reducing activity (MRA) was measured on the top half portion of the steak that had been exposed to light [20]. A $3 \mathrm{~cm} \times 3$ $\mathrm{cm} \times 2 \mathrm{~cm}$ portion was removed from the displayed surface of the steak with no visible fat or connective tissue. The portion was submerged in $0.3 \%$ sodium nitrite solution for $30 \mathrm{~min}$ at $20^{\circ} \mathrm{C} \pm 2$. The oxidized tissue sample was removed from the solution and blotted dry to remove excess nitrite solution from the surface. The sample was vacuum packaged scanned three times for reflectance from $400 \mathrm{~nm}$ to $700 \mathrm{~nm}$ randomly with HunterLab MiniScan ${ }^{\text {mw }}$ EZ Plus Spectrophotometer and averaged for statistical analysis. The samples were then incubated at $30^{\circ} \mathrm{C}$ and rescanned after $2 \mathrm{hr}$ to determine the remaining amount of metmyoglobin (MMb). Surface $\mathrm{MMb}$ was quantified using the equations provided in AMSA Meat Color Guidelines.

\section{Visual color and discoloration score}

Trained visual color panelists $(\mathrm{n}=10)$ evaluated visual display color appearance and surface discoloration once each day from $\mathrm{d} 0$ through d 7 of display. All panelists attended the color orientation session to learn to evaluate the color of steaks. The panelists also were provided descriptive screening and training to obtain quantitative ratings (visual color score) of steak samples on an 8-point scale according to AMSA Meat Color Guidelines. The color of the steaks was visually evaluated on an 8-point scale using color standards ( $1=$ extremely bright cherryred or bright red; $2=$ bright cherry-red or bright red; $3=$ moderately bright cherry-red or bright red; $4=$ slightly bright cherry-red or bright red; $5=$ slightly dark cherry-red or bright red; $6=$ moderately dark red; $7=$ dark red; $8=$ extremely dark red). The displayed steaks were also evaluated for percent of surface discoloration. The discoloration scores were assigned using 7-point scale: $[1=$ no discoloration $(0 \%) ; 2$ $=$ slight discoloration (1 to $19 \%) ; 3=$ small discoloration (20 to $39 \%) ; 4$ $=$ modest discoloration (40 to $59 \%$ ); $5=$ moderate discoloration (60 to $79 \%$ ); 6 = extensive discoloration ( 80 to $99 \%$ ); and $7=$ total discoloration $(100 \%)]$. For all displayed steaks, surface discoloration was estimated as a percentage of surface and sub-metmyoglobin formation. Color scales were used to half-point increments, and discoloration was scored 
Citation: Lee N, Sharma V, Singh R, Mohan A (2014) Effects of Injection Enhancement Carrageenan, Sea-salt, and Potassium Lactate on Beef longissimus lumborum Muscle Sensorial Characteristics and Color Stability. J Food Process Technol 5: 400. doi:10.4172/2157-7110.1000400

Page 3 of 9

\begin{tabular}{|c|c|c|c|}
\hline \multirow{2}{*}{ Quality Grade } & \multirow{2}{*}{ Treatments $^{\mathfrak{\varepsilon}}$} & \multicolumn{2}{|c|}{$\mathrm{pH}$} \\
\hline & & Non-enhanced & Enhanced \\
\hline \multirow{4}{*}{ Choice } & NEC & $5.6^{a}$ & --- \\
\hline & $0.25 \mathrm{CG}$ & $5.7^{\mathrm{abm}}$ & $6.1^{\text {an }}$ \\
\hline & $0.50 \mathrm{CG}$ & $5.8^{\mathrm{bm}}$ & $6.1^{\text {an }}$ \\
\hline & $2.5 \mathrm{KL}$ & $5.9^{b m}$ & $6.2^{\text {an }}$ \\
\hline \multirow{4}{*}{ Select } & NEC & $5.7^{b}$ & --- \\
\hline & $0.25 \mathrm{CG}$ & $5.6^{a b m}$ & $6.1^{\text {an }}$ \\
\hline & $0.50 \mathrm{CG}$ & $5.5^{\mathrm{am}}$ & $6.2^{\text {an }}$ \\
\hline & $2.5 \mathrm{KL}$ & $5.7^{b m}$ & $6.4^{b n}$ \\
\hline
\end{tabular}

${ }^{\mathrm{E}} \mathrm{NEC}=$ Non-enhanced Control; $0.25 \mathrm{CG}=0.25 \% \mathrm{k}$-Carrageenan $+1 \%$ Sea salt + $0.3 \%$ Sodium tripolyphosphate; $0.50 \mathrm{CG}=0.50 \% \mathrm{k}$-Carrageenan $+1 \%$ Sea salt + $0.3 \%$ Sodium tripolyphosphate; $2.5 \mathrm{KL}=2.5 \%$ Potassium lactate $+1 \%$ Sea salt + $0.3 \%$ Sodium tripolyphosphate.

${ }^{a, b}$ Means within a row with different superscript letters differ $(P<0.05)$.

$m, n$ Means within a row with different superscript letters differ $(P<0.05)$.

${ }^{£} \pm \mathrm{SE}=0.12$.

Table 1: $\mathrm{pH}$ muscle $\times$ quality grade $\times$ treatment means and $\mathrm{SE}^{£}$ for steaks

to whole-point increments.

\section{Cooking procedure}

The procedure for cooking was based on American Meat Science Association - Meat Cookery and Sensory Guidelines [21]. Enhanced Choice and Select beef steaks were weighed before cooking and a thermocouple wire (30-gauge, copper-constantan; Omega Engineering, Stamford, CT) was inserted at the geometric center of each steak. Enhanced Choice and Select beef steaks were cooked in a forced-air convection oven (Blodgett, model DFG-102 CH3, G.S. Blodgett Co., Burlington, VT) set at $163^{\circ} \mathrm{C}$. Steaks were turned at an internal temperature of $40^{\circ} \mathrm{C}$ and cooked to an internal temperature of $70^{\circ} \mathrm{C}$, and the temperature was monitored with copper-constantan thermocouples in the approximate geometric center of each steak. Steaks were cooled to room temperature and reweighed for determine the cook yield.

\section{Warner-Bratzler shear force}

The procedure for WBSF was based on American Meat Science Association - Meat Cookery and Sensory Guidelines. Both Choice and Select steaks from all enhancement treatments were cooked, cooled to room temperature, and stored at $2^{\circ} \mathrm{C}$ overnight. Shear force and the work of shearing were determined using a Texture Analyzer (Model TA-XT2i Texture Analyzer; Texture Tech. Corp., Scarsdale, NY) with a 25-kg load cell using a shearing blade (TA 7 - WB blade). As described above, six cooked steaks ( $1.9 \mathrm{~cm}$ wide) were removed parallel to the muscle fiber orientation with a $1.27 \mathrm{~cm}$ corer (G-R Manufacturing Co., Manhattan, KS) attached to an electric drill (Craftsman 3/8" Electric Drill, Sears, Hoffman Estates, IL).

Samples were placed on a slotted plate which was installed into a heavy-duty platform (TA 90). Platform was adjustable to allow the blade to pass through the slotted plate. Crosshead speed of the blade was set at $10 \mathrm{~mm} / \mathrm{sec}$, and the test was triggered by a $0.05 \mathrm{~N}$ contact force. Meanwhile preset and posttest speed was set to $5 \mathrm{~mm} / \mathrm{sec}$. Shear force and the work of shearing was calculated as area under the force deformation curve by the texture analyzer. Shear value was reported as mean of six replicates for each treatment.

\section{Cook yield}

Cook-yield was determined based on the original weight (green weight) of fresh steak. As described above, cooked meat was cooled down at room temperature and weighed. Cook-yield was calculated as follows:

$$
\% \text { Cook yield }=\left(\mathrm{W}_{\text {cooked }} / \mathrm{W}_{\text {initial }}\right) \times 100
$$

\section{Moisture content}

Moisture content (MC, \%) of cooked steaks was determined in duplicate according to the Association of Official Analytical Chemists method (AOAC Official Method 990.03; Thiex, 2009). Approximately, 3 - $3.5 \mathrm{~g}$ sample was removed and ground. The ground sample was weighed and placed in appropriate pre-dried aluminum pans (Fisher Scientific, Cat. No. 08-732-101) and then vacuum dried in a vacuum oven (Cole-Parmer Instrument Comp., Vermon Hills, IL) overnight $100^{\circ} \mathrm{C}$. The $\mathrm{MC}(\%)$ was calculated using following:

$M C, \%=\frac{W_{2}-W_{3}}{W_{2}-W_{1}} \times 100$
where,

$\mathrm{W}_{1}$ = weight of dry aluminum pan.

$\mathrm{W}_{2}$ = weight of wet sample and dry aluminum pan.

$\mathrm{W}_{3}=$ weight of dry sample and dry aluminum pan.

\section{Expressible moisture}

Expressible Moisture (EM, \%) was determined in duplicate using a briefly modified procedure [22,23]. Samples having fixed diameter and $300 \pm 10 \mathrm{mg}$ weight were obtained from cooked steaks. A $2 \times 2 \mathrm{~cm}^{2}$ piece of steak muscle was cut for the EM determination. A \#12 brass corn borer was used to fix the diameter of samples. Cooked steaks were compressed between two parallel plates. A $1.0 \mathrm{~kg}$ load cell was allowed to compress the sample that was placed on a pre-weighed Whatmann filter paper $(\# 1,9 \mathrm{~cm})$ in between two Plexiglass plates for 60s. The moisture soaked filter paper was then weighed to determine the released moisture from the sample. The difference of the muscle weight before and after the compression was calculated. The EM (\%) was calculated as percentage of the uncompressed weight:

$$
\begin{aligned}
& \mathrm{EM}, \%=100 \times\left(\mathrm{W}_{\text {final }}-\mathrm{W}_{\text {initial }}\right) / \text { sample weight } \\
& \text { where, } \quad \mathrm{W}_{\text {final }}=\text { weight of filter paper after compression } \\
& \mathrm{W}_{\text {initial }}=\text { initial weight of filter paper }
\end{aligned}
$$

\section{Statistical analysis}

The data were analyzed using Mixed Procedure of SAS [24]. The experimental design was a randomized complete block with repeated measurements, and each experiment was replicated six times. Color measurements were repeat measurements of the same experimental unit during the retail display period. Triplicate color measurements taken on the same experimental unit were averaged for statistical analysis. The statistical model included the fixed effects of grade (Select and Choice), treatments, display time, and their interaction. Data for all injected strip loin sections were analyzed to permit comparisons among injection treatments. Type- 3 tests of fixed effects for changes in $L^{*}, a^{*}$, and $b^{*}$ and $\mathrm{MMb}$ formation during retail display were evaluated using the Mixed Procedure of SAS. Means were separated using Fisher's protected LSD with Prasad-Rao-Jeske-Kackar-Harville standard errors and the Kenward-Roger degrees of freedom. Highest order interactions were reported when they were significant, or main effects were reported when no interactions were significant. Significance was determined at probability values of $(P<0.05)$. 
Citation: Lee N, Sharma V, Singh R, Mohan A (2014) Effects of Injection Enhancement Carrageenan, Sea-salt, and Potassium Lactate on Beef longissimus lumborum Muscle Sensorial Characteristics and Color Stability. J Food Process Technol 5: 400. doi:10.4172/2157-7110.1000400

Page 4 of 9

\section{Results}

\section{pH measurement}

There was a muscle $\times$ quality grade $\times$ enhancement treatment interaction $(P<0.05)$ for $\mathrm{pH}$ (Table 1$)$. The mean $\mathrm{pH}$ range for the nonenhanced Choice grade steaks ranged between 5.6 and 5.9 and for the Select grade steaks between 5.5 and 5.7. After injection enhancement, mean $\mathrm{pH}$ for both Choice and Select grade steaks varied between 6.1 and 6.4. Enhanced Choice and Select grade steaks had a higher $(P<0.05)$ $\mathrm{pH}$ than non-enhanced steaks.

\section{Instrumental color properties}

Effects of enhancement treatment $\times$ quality grade: In the present experiment, quality grade interacted with treatments and affected instrumental color properties $\left(L^{*}, a^{*}, b^{*}\right.$, Hue angle, and SI). Leastsquare means for quality grade $x$ enhancement treatment interaction effect for CIE $L^{\star}, a^{\star}, b^{\star}, \mathrm{HA}$, and SI - values for both Choice and Select steaks across the $7 \mathrm{~d}$ of retail display are presented in Table 2 . The $L^{*}$ - values for the Choice steaks enhanced with 0.50 CG $(0.50 \%$ $\kappa$-Carr) were lighter (higher $L^{*}$ - values; $\left.P<0.05\right)$ than 0.25 CG $(0.25 \%$ $\kappa$-Carr) and NEC (non-enhanced control). A numerical increase in $L^{\star}$ - value for the Choice steaks enhanced with 0.25 CG was observed as compared to NEC (Table 2). Choice steaks injected with $2.5 \mathrm{KL}(2.5 \%$ potassium lactate) exhibited higher lightness appearance $(P<0.05)$ than all other treatments.

Comparatively, the $L^{\star}$ - values for the Select steaks enhanced with 0.25 and 0.50 CG were observed lighter $(P<0.05)$ than Select steaks enhanced with $2.5 \% \mathrm{KL}$. Enhancement treatment of Select steaks with $2.5 \mathrm{KL}$ was darker in appearance in Select than Choice steaks. Select steaks enhanced with $2.5 \mathrm{KL}$ had the lowest $L^{*}$ - value $(P<0.05)$ and was darkest among all enhancement treatments (Table 2) and NEC.

Choice steaks enhanced with 0.25 CG and 0.50 CG were more red (higher $a^{*}$ - value; $P<0: 05$ ) as compared with $2.5 \mathrm{KL}$ and NEC (Table 2). Injection enhancement of Choice steaks with $0.50 \mathrm{CG}$ showed increased $(P<0.05)$ redness in appearance than those enhanced with 0.25 CG and $2.5 \mathrm{KL}$. Select steaks injected with $2.5 \mathrm{KL}$ exhibited darkening of red color appearance than Choice steaks. Among enhancement treatments, $2.5 \mathrm{KL}$ treatment caused the most darkening of red color in Select steaks. Select steaks enhanced with 0.25 CG and 0.50 CG treatments were also darker red than Choice.

Choice steaks enhanced with $0.25 \mathrm{CG}, 0.50 \mathrm{CG}$, and $2.5 \mathrm{KL}$ were more yellowish (higher $\left.b^{*} ; P<0: 05\right)$ than NEC steaks. Select steaks from the $0.25 \mathrm{CG}, 0.50 \mathrm{CG}$, and $2.5 \mathrm{KL}$ treatments were comparable to Choice steaks in $b^{\star}$ - values.

Intensity of red color appearance of Choice and Select steaks is provided in Table 2. Injected Choice steaks with $2.5 \mathrm{KL}$ treatment displayed increased red color intensity (higher SI - value) than those treated with 0.25 CG and 0.50 CG treatments. Comparatively, Select steaks enhanced with $0.50 \mathrm{CG}$ revealed higher $(P<0: 05)$ red color saturation than $0.25 \mathrm{CG}$ and $2.5 \mathrm{KL}$ treatments. Results show (Table 2) that enhancement with $2.5 \mathrm{KL}$ improved redness intensity in Choice steaks than the Select steaks. The redness intensity was observed to be higher for the Choice steaks than the Select among all enhancement treatment groups.

Injection enhancement of the Choice steaks with treatment $2.5 \mathrm{KL}$ showed higher $(P<0.05)$ hue angle and was different $(P<0.05)$ from the 0.25 and 0.50 CG treatments. Enhancement of the Select steaks with treatment $0.25 \mathrm{CG}$ exhibited higher $(P<0.05)$ hue angle values than those with $0.50 \mathrm{CG}$ and $2.5 \mathrm{KL}$ (Table 2). Hue angle values for the steaks enhanced with $0.50 \mathrm{CG}$ treatment were comparable, and not different $(P>0.05)$.

Effects of quality grade $\times$ display days: Both $a^{*}$ and saturation index (SI) showed a quality grade $\times$ display days interaction $(P<0.05$ Table 3$)$. The redness $\left(a^{*}\right)$ values decreased $(P<0.05)$ progressively during each day of retail display for both Choice and Select steaks. Decreasing redness was as expected for typical meat color deterioration during retail display. However, Choice steaks provided higher $(P<0.05)$ redness $\left(a^{*}\right)$ values than Select steaks from $d 0$ through 7 of the retail display.

The SI values (Table 3) followed similar trend as redness for both Choice and Select steaks. The SI values decreased over time with advancement of the display days for the first $5 \mathrm{~d}$ of the retail display for both Choice and Select steaks (Table 3). The SI values of the Choice steaks were higher than the Select throughout the retail display except for the $\mathrm{d} 5$ and $\mathrm{d} 6$ when it was lower.

Effects of enhancement treatment $\times$ display days: Instrumental color properties for $a^{*}$ and saturation index also showed an enhancement treatment $\times$ display day interaction (Table 4). On $\mathrm{d} 0$, the $a^{*}$ values for both Choice and Select steaks injected with treatments (0.25 CG, $0.50 \mathrm{CG}$, and $2.5 \mathrm{KL}$ ) did not differ from the non-enhanced steaks. On d 1, steaks (both Choice and Select) enhanced with 0.50 CG and $2.5 \mathrm{KL}$ were more red than $0.15 \mathrm{CG}$ and NEC. Steaks enhanced with $0.50 \mathrm{CG}$ and $2.5 \mathrm{KL}$ treatments exhibited a similar pattern of red color deterioration from $\mathrm{d} 1$ to $\mathrm{d} 7$ of retail display. Treatment with 0.50 CG and $2.5 \mathrm{KL}$ demonstrated increased display color stability over 0.25 CG and NEC. Enhanced and non-enhanced steaks (both Choice and Select) showed a similar trend of red color intensity (SI) deterioration over the display time. Enhanced Choice and Select steaks treated with $0.50 \mathrm{CG}$ and $2.5 \mathrm{KL}$ had improved and stabilized redness ( $a^{*}$ values) and redness intensity (SI), unlike steaks treated with 0.25 CG and NEC during $7 \mathrm{~d}$ display.

Visual color evaluation: Visual color evaluation scores for both Choice and Select steaks showed a quality grade $\times$ enhancement treatment $\times$ display days interaction (Table 5) during retail display. Visual color panelists noted that enhanced and non-enhanced Choice steaks were bright cherry red or bright red on $\mathrm{d} 0,1$, and 2 of retail display except Choice steaks enhanced with $2.5 \mathrm{KL}$ was perceived to be slight $(P<0.05)$ bright red in appearance on $\mathrm{d} 2$. On display $\mathrm{d} 2$, Choice steaks enhanced with $0.50 \mathrm{CG}$ tended to appear moderately bright red in color than $0.25 \mathrm{CG}$ and $2.5 \mathrm{~L}$ treatments (Table 5). As display day advanced from d 3 through d 5 of retail display, NEC Choice steaks demonstrated a slight to modest dark red color appearance [higher visual color scores; $(P<0.05)]$ than the enhanced steaks with $0.25 \mathrm{CG}$, $0.50 \mathrm{CG}$, and $2.5 \mathrm{KL}$ treatments. Choice steaks enhanced with $0.25 \mathrm{CG}$ followed a similar trend of red color darkening with advancement of display days from $\mathrm{d} 3$ to $\mathrm{d} 7$. Visual color panelists scored enhanced Choice steaks with $0.25 \mathrm{CG}$ higher $(P<0.05)$ than $0.50 \mathrm{CG}$ and $2.5 \mathrm{KL}$ equivalents. In general, color panelists scored enhancement treatment 0.50 CG very similarly to $2.5 \mathrm{KL}$. Choice steaks enhanced with $0.25 \mathrm{CG}$ were comparable to the Non-Enhanced Control (NEC) and appeared to exhibit similar darkening patterns throughout the display period.

On $\mathrm{d} 0$ of retail display, enhanced and non-enhanced Select steaks received the same $(P>0.05)$ visual color scores (Table 5). On display $\mathrm{d}$ 2, Select steaks enhanced with 0.25 CG and 2.5 KL received higher $(P<0.05)$ visual scores by the panelists than 0.50 CG enhanced Select steaks (Table 5). On d 3, 4, and 5 of retail display, NEC and 0.25 CG 
Citation: Lee N, Sharma V, Singh R, Mohan A (2014) Effects of Injection Enhancement Carrageenan, Sea-salt, and Potassium Lactate on Beef longissimus lumborum Muscle Sensorial Characteristics and Color Stability. J Food Process Technol 5: 400. doi:10.4172/2157-7110.1000400

Page 5 of 9

\begin{tabular}{|c|c|c|c|c|c|c|}
\hline \multirow{2}{*}{ Quality Grade } & \multirow{2}{*}{ Treatment } & \multicolumn{5}{|c|}{ Instrumental color properties } \\
\hline & & $L^{*}$ & $a^{*}$ & $\boldsymbol{b}^{*}$ & Hue angle & Saturation Index \\
\hline \multirow{4}{*}{ Choice } & NEC & $45.4^{\text {as }}$ & $21.0^{a t}$ & $16.6^{a t}$ & $44.3^{b t}$ & $33.7^{\text {at }}$ \\
\hline & $0.25 \mathrm{CG}$ & $46.7^{b s}$ & $24.3^{b t}$ & $17.7^{b s}$ & $44.1^{b s}$ & $35.4^{b t}$ \\
\hline & $0.50 \mathrm{CG}$ & $49.2^{c s}$ & $27.7^{d t}$ & $18.9^{c t}$ & $44.4^{b s}$ & $36.9^{c s}$ \\
\hline & $2.5 \mathrm{KL}$ & $51.6^{d t}$ & $25.6^{c t}$ & $19.0^{c s}$ & $41.3^{\text {as }}$ & $38.6^{d s}$ \\
\hline \multirow{4}{*}{ Select } & NEC & $44.9^{b s}$ & $19.6^{\text {as }}$ & $14.9^{\text {as }}$ & $39.8^{\text {as }}$ & $31.1^{\text {as }}$ \\
\hline & $0.25 \mathrm{CG}$ & $48.6^{c t}$ & $22.7^{b s}$ & $18.1^{b s}$ & $47.0^{c t}$ & $33.1^{\text {bs }}$ \\
\hline & $0.50 \mathrm{CG}$ & $50.8^{d t}$ & $26.0^{d s}$ & $17.7^{b s}$ & $44.5^{b s}$ & $37.2^{c s}$ \\
\hline & $2.5 \mathrm{KL}$ & $42.5^{\text {as }}$ & $23.8^{c s}$ & $21.3^{c t}$ & $41.2^{b s}$ & $37.7^{c s}$ \\
\hline
\end{tabular}

${ }^{\varepsilon} \mathrm{NEC}=$ Non-enhanced Control; $0.25 \mathrm{CG}=0.25 \% \mathrm{k}$-Carrageenan $+1 \%$ Sea salt + $0.3 \%$ Sodium tripolyphosphate; $0.50 \mathrm{CG}=0.50 \% \mathrm{k}$-Carrageenan $+1 \%$ Sea salt + $0.3 \%$ Sodium tripolyphosphate; $2.5 \mathrm{KL}=2.5 \%$ Potassium lactate $+1 \%$ Sea salt + $0.3 \%$ Sodium tripolyphosphate.

$a, b, c, d$ Means with different superscript within a column and within each quality grade (Choice vs Select) differ $(P<0.05)$.

${ }^{s, t}$ Means with different superscript within a column and within the treatment among quality grades differ $(P<0.05)$.

\pm SE for $L^{*}=0.46 ; a^{*}=0.29 ; b^{*}=0.23 ;$ hue angle $=0.21 ;$ and Saturation Index $=$ 0.57

Table 2: LS Means for quality grade $\times$ treatment interaction for instrumental color properties $\left(L^{*}, a^{*}, b^{*}\right.$, Hue angle and Saturation index) for beef strip loins enhanced with different treatments ${ }^{£}$.

\begin{tabular}{|c|c|c|c|c|c|c|c|c|c|}
\hline \multirow{2}{*}{$\begin{array}{l}\text { Color } \\
\text { Properties }\end{array}$} & \multirow{2}{*}{$\begin{array}{l}\text { Quality } \\
\text { Grade }\end{array}$} & \multicolumn{8}{|c|}{ Display Days } \\
\hline & & 0 & 1 & 2 & 3 & 4 & 5 & 6 & 7 \\
\hline \multirow{2}{*}{$a^{*}$} & Choice & $29.7^{b r}$ & $27.4^{b q}$ & $24.8^{b p}$ & $20.3^{\text {bo }}$ & $19.6^{b o}$ & $16.2^{b n}$ & $15.7^{b n}$ & $11.3^{a m}$ \\
\hline & Select & $26.2^{\text {ar }}$ & $25.8^{a r}$ & $21.5^{a q}$ & $18.1^{a p}$ & $17.6^{a p}$ & $14.7^{\mathrm{ao}}$ & $12.8^{a n}$ & $10.8^{a m}$ \\
\hline \multirow{2}{*}{$\begin{array}{l}\text { Saturation } \\
\text { Index }\end{array}$} & Choice & $37.4^{b q}$ & $34.2^{b p}$ & $32.9^{b p}$ & $27.1^{b o}$ & $23.1^{b n}$ & $20.0^{\mathrm{am}}$ & $19.8^{\mathrm{am}}$ & $19.9^{\mathrm{bm}}$ \\
\hline & Select & $34.8^{a q}$ & $30.4^{a p}$ & $29.3^{a p}$ & $24.7^{a o}$ & $20.7^{a n}$ & $19.4^{a m n}$ & $18.6^{\mathrm{am}}$ & $17.8^{a m}$ \\
\hline
\end{tabular}

${ }^{\varepsilon} \mathrm{NEC}=$ Non-enhanced Control; $0.25 \mathrm{CG}=0.25 \% \mathrm{k}$-Carrageenan $+1 \%$ Sea salt + $0.3 \%$ Sodium tripolyphosphate; $0.50 \mathrm{CG}=0.50 \% \mathrm{k}$-Carrageenan $+1 \%$ Sea salt + $0.3 \%$ Sodium tripolyphosphate; $2.5 \mathrm{KL}=2.5 \%$ Potassium lactate $+1 \%$ Sea salt + $0.3 \%$ Sodium tripolyphosphate.

$a, b$ Means with different superscripts within a column for a particular color trait are different $(P<0.05)$

$m, n, o, p, q, r$ Means with different superscripts within a row are different $(P<0.05)$.

\pm SE for $a^{*}=0.67$; Saturation Index $=0.64$

Table 3: LSMeans for quality grade $x$ display days interaction for instrumenta color properties ( $a^{*}$ and Saturation Index) for the raw beef strip loins enhanced with different treatment ${ }^{\varepsilon}$

enhanced Select steaks had higher $(P<0.05)$ visual scores than $0.50 \mathrm{CG}$, and $2.5 \mathrm{KL}$ steaks. As display days advanced, enhanced Select steaks with $2.5 \mathrm{KL}$ were scored lower $(P<0.05)$ than $0.25 \mathrm{CG}, 0.50 \mathrm{CG}$ and NEC. Enhancement of Select steaks with 0.25 CG was comparable to NEC and tended to exhibit a similar darkening pattern throughout the display.

Discoloration scores: Discoloration scores (Table 6) for both Choice and Select steaks showed a quality grade $\times$ treatment $\times$ display days interaction. Visual color panelists found that non-enhanced Choice steaks exhibited surface discoloration at a relatively rapid rate than enhanced steaks over $7 \mathrm{~d}$ of retail display and storage. Injection enhancement of Choice steaks with $2.5 \mathrm{KL}$ displayed improved color stability with little or no surface $(P<0.05)$ discoloration as compared with those enhanced with $0.25 \mathrm{CG}$ and $0.50 \mathrm{CG}$ respectively. Choice steaks enhanced with $0.50 \mathrm{CG}$ discolored at much slower rate $(P<0.05)$ than 0.25 CG and NEC treatments.

A similar trend was observed for Select steaks. However, Choice steaks enhanced with $2.5 \mathrm{KL}$ outperformed all Select steaks (Table 6). Choice and Select steaks enhanced with 0.50 CG showed almost no differences. On display d 2, Select steaks enhanced with 0.25 CG received same discoloration scores as NEC. On $\mathrm{d} 3$ through $\mathrm{d} 7$ of retail display, Select steaks enhanced with 0.25 CG were comparable to NEC Select steaks and discolored more rapidly than steaks enhanced with $0.50 \mathrm{CG}$ and $2.5 \mathrm{KL}$. The rate of discoloration was relatively similar between $0.50 \mathrm{CG}$ and $2.5 \mathrm{KL}$ treatments.

Impact of enhancement treatments on metmyolgobin reducing activity: Results from nitric oxide metmyoglobin reducing assays during display and storage are presented in Figure 1. A higher reduction of $\mathrm{MMb}$ represents higher reducing activity and greater color stability. On d 1 and 2 of retail display, Choice steaks injected with 0.25 CG $(0.25 \% \kappa$-Carr) and 0.50 CG $(0.50 \% \kappa$-Carr $)$ enhancement solutions reduced more $(P<0.05) \mathrm{MMb}$ and displayed higher reducing activity than $2.5 \mathrm{KL}$ enhanced Choice steaks and NEC (Figure 1A). Enhancement treatments $0.25 \mathrm{CG}, 0.50 \mathrm{CG}$, and $2.5 \mathrm{KL}$ demonstrated higher reducing activity (higher MRA) and reduced more than 70\% of MMb as compared to NEC. There was a concentration-dependent effect of $\kappa$-Carr on $\mathrm{MMb}$ reducing activity of Choice steaks enhanced with $0.25 \mathrm{CG}$ and $0.50 \mathrm{CG}$ on $\mathrm{d} 5$ and 7 of retail display. Enhancement of Choice steak with $2.5 \mathrm{KL}$ was found to have persistently higher $(P<$ $0.05)$ reducing activity and higher $\mathrm{MMb}$ reduction as compared with $0.25 \mathrm{CG}, 0.50 \mathrm{CG}$, and NEC on d 2 and $\mathrm{d} 7$ of retail display (Figure $1 \mathrm{~A}$ and $1 \mathrm{~B})$. Comparatively, enhanced Choice steaks with $0.25 \mathrm{CG}$ and 0.50 CG presented a decreasing trend of MRAs on $\mathrm{d} 5$ and $\mathrm{d} 7$ of retail display. Enhancement of Choice steaks with 0.50 CG had higher reducing activity than 0.25 CG and NEC.

A similar trend was observed for Select steaks enhanced with 0.25 CG, 0.50 CG, and 2.5 KL. Injection enhancement of Select steaks with $0.25 \mathrm{CG}$ and $2.5 \mathrm{KL}$ displayed higher $(P<0.05)$ reducing activity and $<$ $65 \% \mathrm{MMb}$ reduction on $\mathrm{d} 1$ of retail display than $0.50 \mathrm{CG}$ and NEC (Figure 1B and 1D). As display days advanced, enhanced Select steaks with $2.5 \mathrm{KL}$ outperformed enhancement treatments $0.25 \mathrm{CG}$ and 0.50 CG and were found to have higher percentages of $\mathrm{MMb}$ reduction on display days 1 through 7 . However, Select steaks enhanced with 0.50 CG performed relatively better than $0.25 \mathrm{CG}$ in reduction $\mathrm{MMb}$ on display d 5 and 7. In general, both Choice and Select steaks enhanced with $0.50 \mathrm{CG}$ and $2.5 \mathrm{KL}$ greater MRA and presented higher MMb reducing ability than 0.25 and NEC treatments (Figure 1).

Oxidation of myoglobin to $\mathrm{MMb}$ is an indicator of meat discoloration and, in some cases, spoilage. Results (Figure 1C and 1D) provide an overview of how enhancement treatments influenced nitric oxide induced myoglobin oxidation and $\mathrm{MMb}$ formation during retail display over 7 days. Most notably, $2.5 \mathrm{KL}$ enhancement outperformed $0.25 \mathrm{CG}$ and $0.50 \mathrm{CG}$ in their abilities to reduce MMb. Although, enhancement with 0.50 CG exhibited higher MMb reducing activity, it was also associated with a continuous decline in reducing capacity as display day advanced from $\mathrm{d} 1$ through $\mathrm{d} 7$.

\section{Impact of enhancement treatments on cooked product sensory characteristics}

Cook yield: The cooked product sensory characteristics (cook yield, expressible moisture, and moisture content) for both Choice and Select steaks are provided in Table 7. Choice steaks enhanced with treatment $0.5 \%$ CG revealed a greater cook yield compared with enhancement treatments $0.25 \mathrm{CG}, 2.5 \mathrm{PL}$, and NEC respectively. Enhancement of Choice steaks with 2.5 PL increased $(\mathrm{P}<0.05)$ the cook yield to $72.6 \%$ as compared to NEC at $67.8 \%$. A similar trend was observed for the Select steaks. However, cook yield for the enhanced Select steaks with 0.5 CG demonstrated a higher cook yield than the Choice steak. Enhancement treatment of the Select steaks with 0.25 and 0.5 CG exhibited greater 
Citation: Lee N, Sharma V, Singh R, Mohan A (2014) Effects of Injection Enhancement Carrageenan, Sea-salt, and Potassium Lactate on Beef longissimus lumborum Muscle Sensorial Characteristics and Color Stability. J Food Process Technol 5: 400. doi:10.4172/2157-7110.1000400

Page 6 of 9

\begin{tabular}{|c|c|c|c|c|c|c|c|c|c|}
\hline \multirow{2}{*}{ Color Properties } & \multirow{2}{*}{ Treatment } & \multicolumn{8}{|c|}{ Display Days } \\
\hline & & 0 & 1 & 2 & 3 & 4 & 5 & 6 & 7 \\
\hline \multirow[t]{4}{*}{$a^{*}$} & NEC & $26.8^{a s}$ & $25.1^{\text {ar }}$ & $21.3^{a q}$ & $17.2^{\mathrm{ap}}$ & $13.7^{a o}$ & $12.8^{\text {ano }}$ & $11.4^{a m n}$ & $10.7^{\mathrm{am}}$ \\
\hline & $0.25 \mathrm{CG}$ & $27.3^{\text {ar }}$ & $26.2^{a b r}$ & $22.2^{\mathrm{aq}}$ & $17.4^{a p}$ & $15.2^{\text {ao }}$ & $13.5^{\text {ano }}$ & $10.9^{\mathrm{am}}$ & $12.3^{b m n}$ \\
\hline & $0.50 \mathrm{CG}$ & $26.5^{a p}$ & $27.3^{b c p}$ & $27.6^{b p}$ & $24.6^{c o}$ & $23.2^{\text {bo }}$ & $19.0^{b n}$ & $16.0^{\mathrm{bm}}$ & $15.2^{\mathrm{cm}}$ \\
\hline & $2.5 \mathrm{KL}$ & $27.2^{a p}$ & $28.8^{c p q}$ & $26.5^{b p}$ & $22.7^{\text {bo }}$ & $22.9^{b o}$ & $19.8^{b n}$ & $18.9^{\mathrm{cmn}}$ & $17.5^{d m}$ \\
\hline \multirow[t]{4}{*}{ Saturation Index } & NEC & $35.4^{a p}$ & $28.2^{a o}$ & $27.5^{\mathrm{ao}}$ & $21.4^{a n}$ & $15.4^{\mathrm{am}}$ & $16.6^{a m}$ & $16.2^{\mathrm{am}}$ & $15.8^{\mathrm{am}}$ \\
\hline & $0.25 \mathrm{CG}$ & $38.2^{b q}$ & $31.0^{b p}$ & $29.2^{\text {bo }}$ & $24.6^{b n}$ & $19.9^{b m}$ & $19.3^{\mathrm{bm}}$ & $19.2^{\mathrm{bm}}$ & $20.3^{b m}$ \\
\hline & $0.50 \mathrm{CG}$ & $37.5^{b p}$ & $36.7^{d p}$ & $35.9^{d p}$ & $28.2^{c o}$ & $27.5^{d o}$ & $24.8^{d n}$ & $19.7^{\mathrm{bm}}$ & $19.9^{b m}$ \\
\hline & $2.5 \mathrm{KL}$ & $37.3^{b r}$ & $33.3^{c q}$ & $33.8^{c q}$ & $30.3^{b p}$ & $25.2^{\mathrm{co}}$ & $21.9^{c n}$ & $16.8^{\mathrm{am}}$ & $16.4^{\mathrm{am}}$ \\
\hline
\end{tabular}

${ }^{\mathrm{E}} \mathrm{NEC}=$ Non-enhanced Control; $0.25 \mathrm{CG}=0.25 \% \mathrm{k}$-Carrageenan $+1 \%$ Sea salt $+0.3 \%$ Sodium tripolyphosphate; $0.50 \mathrm{CG}=0.50 \% \mathrm{k}-\mathrm{Carrageenan}+1 \%$ Sea salt $+0.3 \%$ Sodium tripolyphosphate; $2.5 \mathrm{KL}=2.5 \%$ Potassium lactate $+1 \%$ Sea salt $+0.3 \%$ Sodium tripolyphosphate.

$a, b, c, d$ Means with different superscripts within a column and within the same quality grade are different $(P<0.05)$

$m, n, o, p, q, r, s$ Means with different superscripts within a row are different $(P<0.05)$.

\pm SE for $a^{*}=0.79$; Saturation Index $=0.77$

Table 4: LSMeans for treatment $\times$ display days interaction for instrumental color properties ( $a^{*}$ and Saturation Index) for raw beef strip loins enhanced with different treatment ${ }^{£}$.

\begin{tabular}{|c|c|c|c|c|c|c|c|c|c|}
\hline \multirow{2}{*}{ Quality grade } & \multirow{2}{*}{ Treatment } & \multicolumn{8}{|c|}{ Display Days } \\
\hline & & 0 & 1 & 2 & 3 & 4 & 5 & 6 & 7 \\
\hline \multirow[t]{4}{*}{ Choice } & NEC & $2.4^{a m x}$ & $2.9^{\operatorname{bn} x}$ & $2.8^{b n x}$ & $5.4^{\operatorname{cox}}$ & $6.1^{d p x}$ & $6.9^{e q x}$ & $7.1^{\text {eqx }}$ & $7.0^{f q x}$ \\
\hline & 0.25 CG & $2.8^{\mathrm{cmx}}$ & $2.9^{a b m x}$ & $3.1^{b m x}$ & $4.8^{\operatorname{cnx}}$ & $5.6^{d o x}$ & $6.1^{e p x}$ & $7.5^{f q y}$ & $7.4^{f q x}$ \\
\hline & $0.50 \mathrm{CG}$ & $2.6^{b m x}$ & $2.3^{a b m x}$ & $2.2^{a m x}$ & $3.3^{\operatorname{cnx} x}$ & $4.1^{d o x}$ & $4.8^{e p x}$ & $5.3^{f q x}$ & $6.5^{g r x}$ \\
\hline & $2.5 \mathrm{KL}$ & $2.3^{a m x}$ & $2.9^{b n x}$ & $4.2^{\operatorname{cop} x}$ & $4.4^{c p d x}$ & $4.6^{d e p x}$ & $4.8^{e f p q x}$ & $5.2^{g q y}$ & $5.1^{\text {fgrx }}$ \\
\hline \multirow[t]{4}{*}{ Select } & NEC & $2.8^{a m y}$ & $3.5^{\text {bny }}$ & $3.9^{\text {bny }}$ & $5.5^{\operatorname{cox}}$ & $6.9^{d p y}$ & $7.2^{e p y}$ & $7.7^{\text {fay }}$ & $7.6^{f a y}$ \\
\hline & $0.25 \mathrm{CG}$ & $2.5^{a m y}$ & $3.3^{\text {bny }}$ & $4.0^{\text {coy }}$ & $5.2^{d p y}$ & $6.1^{\text {eqy }}$ & $6.4^{\text {eqrx }}$ & $6.9^{f f x}$ & $7.4^{g s x}$ \\
\hline & $0.50 \mathrm{CG}$ & $2.4^{a m y}$ & $2.7^{\text {any }}$ & $2.8^{b n y}$ & $3.8^{\text {coy }}$ & $4.0^{c p x}$ & $5.7^{d q y}$ & $5.9^{d r x}$ & $6.8^{\text {erx }}$ \\
\hline & $2.5 \mathrm{KL}$ & $2.6^{a m x}$ & $3.1^{b n x}$ & $3.9^{\operatorname{cox}}$ & $4.5^{d p x}$ & $4.5^{d p x}$ & $4.7^{d p x}$ & $4.6^{d p x}$ & $5.2^{\text {eqx }}$ \\
\hline
\end{tabular}

${ }^{\varepsilon} \mathrm{NEC}=$ Non-enhanced Control; $0.25 \mathrm{CG}=0.25 \% \mathrm{~K}$-Carrageenan $+1 \%$ Sea salt $+0.3 \%$ Sodium tripolyphosphate; $0.50 \mathrm{CG}=0.50 \% \mathrm{~K}-\mathrm{Carrageenan}+1 \%$ Sea salt $+0.3 \%$ Sodium tripolyphosphate; $2.5 \mathrm{KL}=2.5 \%$ Potassium lactate $+1 \%$ Sea salt $+0.3 \%$ Sodium tripolyphosphate.

$a, b, c, d$ Means with different superscripts within a row are different $(P<0.05)$.

$x, y$ Means with different superscripts within a row and within the same treatment and among the quality grades are different $(P<0.05)$.

$m, n, o, p, q, r, s$ Means with different superscripts within a column and within same quality grade are different $(P<0.05)$.

Table 5: LSMeans for quality grade $\times$ treatment $\times$ display days interaction for visual color evaluation for beef strip loins enhanced with different treatments ${ }^{£} . \pm S E$ for visual color score $=0.17$.

\begin{tabular}{|c|c|c|c|c|c|c|c|c|c|}
\hline \multirow{2}{*}{ Quality grade } & \multirow{2}{*}{ Treatment } & \multicolumn{8}{|c|}{ Display Days } \\
\hline & & 0 & 1 & 2 & 3 & 4 & 5 & 6 & 7 \\
\hline \multirow[t]{4}{*}{ Choice } & NEC & $1.1^{a m x}$ & $1.5^{a b n x}$ & $1.8^{\text {bnx }}$ & $3.2^{\operatorname{cox}}$ & $6.1^{d p y}$ & $6.3^{d p x}$ & $6.9^{e q x}$ & $6.9^{\text {erx }}$ \\
\hline & $0.25 \mathrm{CG}$ & $1.1^{a m x}$ & $1.3^{a m x}$ & $1.2^{a m x}$ & $2.2^{b n x}$ & $4.9^{\operatorname{cox}}$ & $6.3^{d p x}$ & $6.6^{d p q x}$ & $6.7^{d q x}$ \\
\hline & $0.50 \mathrm{CG}$ & $2.1^{a m y}$ & $2.2^{a m y}$ & $2.1^{\text {amy }}$ & $2.8^{\text {bny }}$ & $4.1^{\operatorname{cox}}$ & $5.2^{d p x}$ & $5.4^{d p x}$ & $6.1^{\text {eqx }}$ \\
\hline & $2.5 \mathrm{KL}$ & $2.2^{\text {amy }}$ & $2.2^{a m y}$ & $3.2^{\text {bny }}$ & $3.4^{\text {bny }}$ & $3.5^{b c n x}$ & $3.9^{\operatorname{cox}}$ & $4.9^{d p x}$ & $4.8^{d q x}$ \\
\hline \multirow[t]{4}{*}{ Select } & NEC & $1.1^{a m x}$ & $1.4^{a m y}$ & $2.3^{\text {bny }}$ & $3.8^{\operatorname{cox}}$ & $5.7^{d p x}$ & $6.2^{\operatorname{cox}}$ & $6.7^{f p x}$ & $6.9^{f p x}$ \\
\hline & 0.25 CG & $2.1^{\text {amy }}$ & $2.2^{a m y}$ & $2.3^{\text {amy }}$ & $4.2^{\text {bny }}$ & $5.9^{\text {coy }}$ & $6.3^{c d p x}$ & $6.6^{\text {degx }}$ & $6.8^{e q x}$ \\
\hline & $0.50 \mathrm{CG}$ & $1.8^{a b m x}$ & $1.5^{a m x}$ & $1.7^{a m x}$ & $2.2^{\text {bny }}$ & $4.8^{\text {coy }}$ & $5.2^{c d p x}$ & $5.6^{\operatorname{deq} x}$ & $5.9^{\text {erx }}$ \\
\hline & $2.5 \mathrm{KL}$ & $1.3^{a m x}$ & $1.5^{a m x}$ & $2.1^{b n x}$ & $2.6^{\operatorname{cox}}$ & $3.4^{d p x}$ & $4.8^{\text {eqy }}$ & $5.8^{f y}$ & $5.7^{f r y}$ \\
\hline
\end{tabular}

${ }^{\varepsilon} \mathrm{NEC}=$ Non-enhanced Control; $0.25 \mathrm{CG}=0.25 \% \mathrm{~K}$-Carrageenan $+1 \%$ Sea salt $+0.3 \%$ Sodium tripolyphosphate; $0.50 \mathrm{CG}=0.50 \% \mathrm{~K}-\mathrm{Carrageenan}+1 \%$ Sea salt $+0.3 \%$ Sodium tripolyphosphate; $2.5 \mathrm{KL}=2.5 \%$ Potassium lactate $+1 \%$ Sea salt $+0.3 \%$ Sodium tripolyphosphate.

$a, b, c, d$ Means with different superscripts within a row are different $(P<0.05)$.

$x, y$ Means with different superscripts within a row and within the same treatment and among the quality grades are different $(P<0.05)$.

$m, n, o, p, q, r$ Means with different superscripts within a column and within a quality grade (within Choice or within Select) are different $(P<0.05)$.

Table 6: LSMeans for quality grade $\times$ treatment $\times$ display days interaction for discoloration scores for beef strip loins enhanced with different treatments ${ }^{£} \pm$ SE for discoloration score $=0.19$

$(\mathrm{P}<0.05)$ cook yield as compared with $2.5 \mathrm{PL}$ and NEC. As compared to NEC with $63.1 \%$ cook yield, $2.5 \% \mathrm{PL}$ treatment showed a higher $((\mathrm{P}$ $<0.05)$ ) cook yield of $66.4 \%$.

Expressible moisture: Results obtained in this study shows that there was grade specific differences in expressible moisture between Choice and Select steaks enhanced with treatments 0.25 CG and 0.5 CG.
In general, Choice grade steaks exhibited higher expressible moisture than the Select steaks. Expressible moisture for Choice steaks enhanced with 0.25 CG and 0.5 CG had higher amount of expressible moisture and were significantly different $(\mathrm{P}<0.05)$ from all other treatments. Enhancement of both Choice and Select steaks demonstrated higher expressible moisture than NEC. 

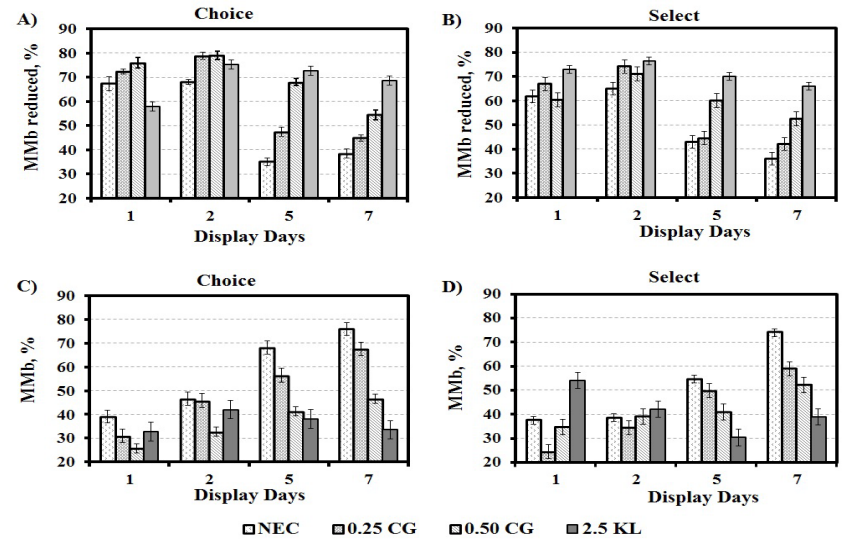

Figure 1: Effects of enhancement treatments ${ }^{a}$ on nitric oxide metmyoglobin reducing activity $(A$ and $B)$ and \% metmyoglobin $(C$ and $D ; M M b, \%)$ of beef strip loin during a $7 \mathrm{~d}$ retail display and storage at $2^{\circ} \mathrm{C}$. Larger values for $L^{*}, a^{*}$ and $b^{*}$ indicate a lighter, redder, or more yellow color, respectively.

${ }^{a} \mathrm{NEC}=$ Non-enhanced Control; $0.25 \mathrm{CG}=0.25 \% \mathrm{k}$-Carrageenan $+1 \%$ Sea salt $+0.3 \%$ Sodium tripolyphosphate; $0.50 \mathrm{CG}=0.50 \% \mathrm{k}$-Carrageenan $+1 \%$ Sea salt $+0.3 \%$ Sodium tripolyphosphate; $2.5 \mathrm{KL}=2.5 \%$ Potassium lactate $+1 \%$ Sea salt $+0.3 \%$ Sodium tripolyphosphate

Moisture content: Experimental outcomes of this study indicate that Choice quality grade steaks had moisture content than the Select grade steaks. Enhancement treatment with $0.25 \mathrm{CG}, 0.5 \mathrm{CG}$, and 2.5 PL did not show grade and treatment specific differences in moisture content. However, Choice steaks exhibited a trend of higher moisture content than the Select steaks.

Warner-Bratzler shear force: The results for Warner-Bratzler Shear Force (WBSF) values are provided in Table 7. Enhancement treatments used in this study indicate a grade specific tenderness response for both Choice and Select steaks. Enhancement of Choice steaks with $0.50 \mathrm{CG}$ resulted in being tenderer than those enhanced with $0.25 \mathrm{CG}$ or $2.5 \mathrm{PL}$. There were no differences $(\mathrm{P}>0.05)$ in WBSF for enhanced Choice steaks with 0.25 CG or NEC. Conversely, Choice steaks enhanced with $2.5 \mathrm{PL}$ were less tender $(\mathrm{P}<0.05)$ than other treatments including non-enhanced steaks.

Select steaks enhanced with 0.25 CG or 0.50 treatments more tender than steaks enhanced with $2.5 \mathrm{PL}$ or NEC. The results show distinct grade specific differences in tenderness due to enhancement treatments. Enhancement of Select steaks with 0.50 CG resulted in being tenderer than those enhanced with 0.25 CG or 2.5 PL. The WBSF results showed differences $(\mathrm{P}<0.05)$ for $2.5 \mathrm{PL}$ enhanced Select steaks as compared to NEC.

\section{Discussion}

A continuous challenge in the meat industry is to provide consumers with a consistent, high quality product that meets their expectations. The current industry practices of using the same enhancement strategy on different USDA beef quality grade may not be either economical or necessary. We hypothesized that color stability and sensory characteristics of enhanced beef is influenced by ingredients functionality and USDA quality grade specific. The main objective of this study was to evaluate the effects of injection enhancement with solutions containing $\kappa$-Carr, sodium tripolyphosphate, potassium lactate, and sea salt retail display attributes and color stability traits of both Choice and Select strip loins. The results of this study suggest that an enhancement strategy for beef is both ingredient and quality grade specific, and therefore, the meat industry should consider optimizing their approach to meat enhancement strategy based on current usage of meat quality grades. We observed that the increased concentration of enhancement solutions containing $\kappa$-Carr from 0.25 to $0.50 \%$ in the finished product influenced color stability of both Choice and Select grade beef used in this study. Overall, results clearly indicate that that USDA beef quality grading system can positively influence quality characteristics and beef color stability.

Differences in muscle composition, distribution of inter- and intramuscular fats and inherent metabolic characteristics should be considered critical to optimizing beef enhancement strategy. Differences in color stability between the Choice and Select steaks has been described $[25,26]$ to be attributed to their intrinsic muscle composition properties influencing $\mathrm{MMb}$ reducing activity and endogenous enzyme activity. Thus, the effects of non-meat ingredients on enhanced beef color stability and sensory characteristics may be quality grade specific.

In the literature, variation in quality grades affecting quality traits are often measured using multiple sensory traits describing juiciness, tenderness, and flavor. Measurement of color variables shows that differences in color traits arise because of variations in quality grades; inherent biochemical traits like myoglobin oxidation and reducing capacity are often ignored [27]. Our study shows that differences in quality grades of beef do not follow a definitive pattern of meat color degradation. However, these quality traits (instrumental color and color stability) may vary because of differences in the inherent reducing capacity of muscles or differences in reducing capacity. To design strategies to reduce variation in color-life of a given muscle from different quality grades requires more information on what causes those variations. Thus, we addressed the question of whether color variations at the end of display and color stability change during display may be due to differences in beef quality grades. Differences in the inherent reducing capacity of muscle and the biochemical processes that affect meat color stability should be investigated further to explain this variation

Results of previous studies [28] suggest that certain postmortem biochemical phenomena (oxygen consumption, metmyoglobin formation, and NADH content) affects beef color stability.

Knock et al. reported that steaks from muscles injected with potassium lactate, with or without sodium acetate, had increased color stability, but were darker than non-enhanced control steaks. Lawrence et al. reported an improvement in display color stability with enhancements. In their study, enhancing of USDA Select strip loins with $2 \% \kappa$-Carr resulted in redder steaks (higher $a^{*}$ - value) than those enhanced with $1 \% \kappa$-Carr; enhancement with only sodium phosphate plus salt solution reduced color stability.

We did find a decrease of redness and red color intensity ( $a^{*}$ and SI) during retail display, but we also observed that Choice steaks deteriorated in red color more slowly than Select steaks. Typically, color stability is a relative term related to any of the color or color change variables when measured on $\mathrm{d} 6$. Oxygen consumption, mitochondrial activity, NADH content, and reducing ability all affect meat color stability. Meat quality grade may affect the rate of oxygen consumption and how readily myoglobin binds with oxygen to create oxidative conditions that favor metmyoglobin formation. In the present experiment, although oxygen consumption was not measured, Choice steaks may have had lower oxygen consumption and more reducing activity than Select steaks. Some researchers [29] have suggested 


\begin{tabular}{|l|c|c|c|c|c|}
\hline \multirow{2}{*}{ Quality Grade } & \multirow{2}{*}{ Treatment } & \multicolumn{4}{|c|}{ Cooked steaks sensory characteristics } \\
\cline { 3 - 6 } & & CY $^{\mathbf{x}} \%$ & EM $^{y}, \%$ & MC $^{\mathbf{z}}, \%$ & $\begin{array}{c}\text { Shear } \\
\text { Value (N) }\end{array}$ \\
\hline Choice & NE & $67.2^{a}$ & $2.5^{a}$ & $63.8^{a}$ & $37.7^{b}$ \\
\hline Choice & $0.25 \mathrm{CG}$ & $76.7^{c}$ & $3.1^{b}$ & $64.0^{a}$ & $36.6^{b}$ \\
\hline Choice & $0.5 \mathrm{CG}$ & $81.8^{d}$ & $4.8^{c}$ & $63.2^{a}$ & $32.3^{a}$ \\
\hline Choice & $2.5 \mathrm{PL}$ & $71.3^{b}$ & $2.7^{a}$ & $62.1^{b}$ & $40.2^{c}$ \\
\hline Select & $\mathrm{NE}$ & $63.1^{a}$ & $2.1^{a}$ & $61.1^{a}$ & $46.4^{c}$ \\
\hline Select & $0.25 \mathrm{CG}$ & $69.3^{b}$ & $7.7^{c}$ & $59.3^{a}$ & $38.5^{b}$ \\
\hline Select & $0.5 \mathrm{CG}$ & $86.2^{d}$ & $8.6^{d}$ & $58.8^{a}$ & $25.8^{a}$ \\
\hline Select & $2.5 \mathrm{PL}$ & $66.4^{c}$ & $2.8^{b}$ & $60.1^{a}$ & $43.6^{a}$ \\
\hline
\end{tabular}

${ }^{£}$ Treatment NE $=$ Non-enhanced; $0.25 \mathrm{CG}=0.25 \%$ Carrageenan $+1 \%$ Sea salt + $0.3 \%$ Sodium tripolyphosphate; 0.5 CG $=0.5 \%$ Carrageenan $+1 \%$ Sea Salt $+0.3 \%$ Sodium tripolyphosphate; $2.5 \mathrm{PL}=2.5 \%$ Potassium lactate $+1 \%$ Sea Salt $+0.3 \%$ Sodium tripolyphosphate.

${ }^{y} \mathrm{CY}=$ expressible moisture

${ }^{y} \mathrm{EM}=$ expressible moisture

${ }^{z} \mathrm{MC}=$ moisture content

a, b, c, d Means with different superscript letters within a column and within each quality grade differ $(P<0.05)$

$\pm S E=1.88$ for WBSF; 1.1 for $\mathrm{CY} ; 0.73$ for $\mathrm{EM}$; and 0.91 for $\mathrm{CY}$.

Table 7: Results summarizing the effects of injection enhancement of Choice and Select steaks on cook yield ${ }^{x}$, expressible moisture ${ }^{y}$, moisture content ${ }^{2}$, and WarnerBratzler shear force (WBSF)

that differences in inherent metabolic characteristics of postmortem muscles influence metabolic activity and thus become a limiting factor on meat color-life.

Color panelists observed that non-enhanced Choice and Select steaks darkened more rapidly than enhanced steaks. Among enhanced steaks, the higher level of enhancement ingredient $\kappa$-Carr (from $0.25 \%$ to $0.50 \%$ ) showed greater color stability with lower visual color scores.

Incorporating non-meat ingredients often mitigates differences in color stability. Other researchers have reported higher visual and discoloration scores for steaks enhanced with potassium lactate, which caused a darker appearance. Inclusion of lactate in the enhancement solution increases color stability but also results in darker muscle color [30]. The increased loss of redness over the retail display time may be due to a decrease in metmyoglobin-reducing activity. The brownish color of metmyoglobin begins to appear on the surface of steaks as meat loses its ability to reduce metmyoglobin to oxymyoglobin and $a^{*}$ - values decrease [31].

In general, Choice steaks enhanced with a solution containing $0.50 \mathrm{CG}$ or $2.5 \mathrm{KL}$ exhibited superior color stability and retail display properties and had less perceptible discoloration scores than the Select steaks or non-enhanced steaks. Regardless of quality grade differences, steaks enhanced with a solution containing $0.50 \mathrm{CG}$ or $2.5 \mathrm{KL}$ discolored at a relatively slower rate than $0.25 \mathrm{CG}$ and non-enhanced steaks.

Injection enhanced beef Select and Choice steaks used in this study had an extended color shelf-life, especially with 0.50 CG solution. When $2.5 \mathrm{KL}$ was used to enhance the steaks, color shelf-life was also extended, but most steaks, of both grades, were darker in color. Thus, using 0.50 CG has similar results on beef color and color stability but does not darken the color. Lawrence et al., evaluated enhancement of beef longissimus muscles and reported improved retail display properties and overall color stability.

The results of this study show differences in cook yield, expressible moisture, moisture content, and tenderness due to quality grades assigned to similar enhancement strategies. Results suggest that similar enhancement strategy applied to Choice and Select steaks were quality grade specific. More specifically, enhancement treatments with 0.50 CG appeared to show distinct improvement in cook-yield, expressible moisture, and WBSF values. Other studies have found that injectionenhancement of beef muscles results in decreased shear force values compared to non-enhanced steaks. In a similar study, Lawrence et al., demonstrated that enhancement of beef longissimus muscles with a phosphate and salt solution or a calcium lactate plus beef broth or carrageenan with rosemary extract solution. These authors found no differences in WBSF among all treatments. Knock et al., reported that steaks enhanced with sodium acetate had lower shear force than control steaks or steaks enhanced with potassium lactate.

Trends from the results of this study indicate that sensory characteristics of the steaks was quality grade specific and that enhancement with $0.50 \mathrm{CG}$ resulted in more tender and juicier steaks. In general, Choice steaks exhibited higher expressible moisture, cook yield, and tenderness than the Select steaks assigned to similar enhancement treatments. The non-enhanced steaks from Choice grade were higher in tenderness and were tenderer. This indicates that injection enhancement effects are muscle quality grade specific and that different muscle types and cuts may respond differently within a specific quality grades. This study showed that within a similar enhancement treatment, Choice steaks were tenderer and juicy as compared to Select steaks.

This study was designed to address an underlying issue that a similar enhancement strategy for processing beef muscles with different physiological make-up (Choice or Select) will offer consumers with inconsistent and undesirable processed product. In order to provide consumers with consistent and desirable products, it is necessary to fully understand the quality grade specific enhancement treatments effects. The processed product with similar treatment regimen on different quality grades will affect beef quality traits, including palatability factors differently. Providing consumers with a consistent and high quality beef is of utmost importance and in order to maintain customer satisfaction meat industry should focus on processing strategy that will allow for repeat purchases.

Tenderness is the most important palatability attribute [32]; however, there is huge variation in tenderness among different muscles and cuts. Quality grade specific tenderness issues exist in beef steaks purchased at the retail level [33]. Additionally, consumers have the ability to determine tenderness and many are willing to pay a premium for "guaranteed tender" steaks [34].

In summary, Choice steaks enhanced with 0.50 CG had improved color stability while $2.5 \mathrm{KL}$ solution induced darkening in enhanced steaks. Enhanced Select steaks exhibited similar characteristics, but $2.5 \mathrm{KL}$ solution caused more darkening. Choice steaks had superior color stability with lower perceptible discoloration scores than Select or non-enhanced steaks. Regardless of quality grade differences, steaks enhanced with solutions containing $0.50 \mathrm{CG}$ or $2.5 \mathrm{KL}$ discolored more slowly throughout $7 \mathrm{~d}$ of display than non-enhanced steaks. Thus, using a hydrocolloid solution, like the CG solution we used, may effectively maintain red color and reduce negative visual sensory attributes.

\section{Conclusion}

Our study showed using 0.50 CG in the enhancement formulation is effective in improving color and cooked product attributes while minimizing quality inconsistencies during retail merchandizing of 
Citation: Lee N, Sharma V, Singh R, Mohan A (2014) Effects of Injection Enhancement Carrageenan, Sea-salt, and Potassium Lactate on Beef longissimus lumborum Muscle Sensorial Characteristics and Color Stability. J Food Process Technol 5: 400. doi:10.4172/2157-7110.1000400

fresh beef. The effects on meat color stability of packaging, postmortem age, and display conditions during the cold chain management and retail distribution are pre-requisite to maintaining extended color shelf-life and color stability, but our results clearly show that using a hydrocolloid in the enhancement formulation, in combination with sodium tripolyphosphate and sea-salt, will stabilize color life and improve palatability characteristics. These results should provide the beef industry with new strategies for producing beef that meets consumer sensory expectations during retail purchasing and consistency in quality attributes that should, in turn, ensure repeat purchases and consumption of beef.

\section{References}

1. Beriain MJ, Sánchez M, Carr TR (2009) A comparison of consumer sensory acceptance, purchase intention, and willingness to pay for high quality United States and Spanish beef under different information scenarios. J Anim Sci 87 3392-3402.

2. Hoffman L, Vermaak A, Muller N (2012) Physical and chemical properties of selected beef muscles infused with a phosphate and lactate blend. S Afr J Anim Sci 42: 317-340.

3. Knock RC, Seyfert M, Hunt MC, Dikeman ME, Mancini RA, et al. (2006) Effects of potassium lactate, sodium chloride, and sodium acetate on surface shininess/gloss and sensory properties of injection-enhanced beef strip-loin steaks. Meat Sci 74: 319-326.

4. Mancini RA, Hunt MC (2005) Current research in meat color. Meat Sci 71 100-121.

5. Mohan A, Hunt MC, Barstow TJ, Houser TA, Muthukrishnan S (2010) Effects of malate, lactate, and pyruvate on myoglobin redox stability in homogenates of three bovine muscles. Meat Sci 86: 304-310.

6. Knock RC, Seyfert M, Hunt MC, Dikeman ME, Mancini RA, et al. (2006) Effects of potassium lactate, sodium chloride, sodium tripolyphosphate, and sodium acetate on colour, colour stability, and oxidative properties of injectionenhanced beef rib steaks. Meat Sci 74: 312-318

7. Lawrence TE, Dikeman ME, Hunt MC, Kastner CL, Johnson DE (2004) Effects of enhancing beef longissimus with phosphate plus salt, or calcium lactate plus non-phosphate water binders plus rosemary extract. Meat Sci 67: 129-137.

8. Seyfert M, Hunt MC, Mancini RA, Hachmeister KA, Kropf DH, et al. (2005) Beef quadriceps hot boning and modified-atmosphere packaging influence properties of injection-enhanced beef round muscles. J Anim Sci 83: 686-693.

9. Seyfert M, Mancini RA, Hunt MC, Tang J, Faustman C, et al. (2006) Color stability, reducing activity, and cytochrome $c$ oxidase activity of five bovine muscles. J Agric Food Chem 54: 8919-8925.

10. Bater B, Descamps O, Maurer A (1992) Quality characteristics of hydrocolloidadded oven-roasted turkey breasts. J Food Sci 57: 1068-1070.

11. Barbut S, Mittal G (1992) Use of carrageenans and xanthan gum in reduced fat breakfast sausages. Lebensmittel-Wissenschaft Technologie 25: 509-513.

12. Xiong Y, Noel D, Moody W (1999) Textural and sensory properties of low-fat beef sausages with added water and polysaccharides as affected by $\mathrm{pH}$ and salt. J Food Sci 64: 550-554.

13. Lin K, Ketton J (1998) Textural and physicochemical properties of low-fat precooked ground beef patties containing carrageenan and sodium alginate. J Food Sci 63: 571-574.

14. Huang C, Mikel W, Jones W (1997) Carrageenan influences on the characteristics of restructured normal and pale, soft, and exudative hams. Muscle Foods 8: 85-93.

15. Pietrasik Z, Jarmoluk A (2003) Effect of sodium caseinate and k-carrageenan on binding and textural properties of pork muscle gels enhanced by microbial transglutaminase addition. Food Res Int 36: 285-294

16. Prabhu G, Sebranek J (1997) Quality Characteristics of Ham Formulated with Modified Corn Starch and Kappa-Carrageenan. J Food Sci 62: 198-202.

17. Shand P, Sofos J, Schmidt G (1994) Kappa-carrageenan, sodium chloride and temperature affect yield and texture of structured beef rolls. J Food Sci 59 : 282-287.
18. Candogan K, Kolsarici N (2003) The effects of carrageenan and pectin on some quality characteristics of low-fat beef frankfurters. Meat Sci 64: 199-206

19. American Meat Science Association (2012) Guidelines for meat color evaluation.

20. Sammel L, Hunt M, Kropf D, Hachmeister K, Kastner C, et al. (2002) Influence of chemical characteristics of beef inside and outside semimembranosus on color traits. J Food Sci 67: 1323-1330.

21. American Meat Science Association (1978) Guidelines for Cookery and Sensory Evaluation of Meat, American Meat Science Association.

22. Wierbicki E, Deatherage F (1958) Water content of meats, determination of water-holding capacity of fresh meats. J Agric Food Chem 6: 387-392.

23. Jauregui C, Regenstein J, Baker R (1981) A simple centrifugal method fo measuring expressible moisture, a water-binding property of muscle foods. J Food Sci 46: 1271-1271.

24. SAS Institute Inc (2009) Cary N: SAS Release 9.3.

25. Ledward DA (1985) Post-slaughter influences on the formation of metyyoglobin in beef muscles. Meat Sci 15: 149-171.

26. McKenna DR, Mies PD, Baird BE, Pfeiffer KD, Ellebracht JW, et al. (2005) Biochemical and physical factors affecting discoloration characteristics of 19 bovine muscles. Meat Sci 70: 665-682.

27. Page JK, Wulf DM, Schwotzer TR (2001) A survey of beef muscle color and pH. J Anim Sci 79: 678-687.

28. Mancini R, Kim Y, Hunt M, Lawrence T (2004) How does lactate-enhancement stabilize beef color? Proceedings of American Meat Sci Assoc 8: 13.

29. Estabrook RW (1967) Mitochondrial respiratory control and the polarographic measurement of ADP: O ratios. Meth Enzymol 10: 41-47.

30. Mancini R, Hunt M, Hachmeister K, Seyfert M, Kropf D, et al. (2005b) The utility of lactate and rosemary in beef enhancement solutions: Effects on longissimus color changes during display. J Muscle Foods 16: 27-36.

31. O'Keeffe M, Hood DE (1982) Biochemical factors influencing metmyoglobin formation on beef from muscles of differing colour stability. Meat Sci 7: 209

32. Miller MF, Huffman KL, Gilbert SY, Hamman LL, Ramsey CB (1995) Retail consumer acceptance of beef tenderized with calcium chloride. J Anim Sci 73: 2308-2314.

33. George MH, Tatum JD, Belk KE, Smith GC (1999) An audit of retail beef loin steak tenderness conducted in eight U.S. cities. J Anim Sci 77: 1735-1741.

34. Miller MF, Carr MA, Ramsey CB, Crockett KL, Hoover LC (2001) Consumer thresholds for establishing the value of beef tenderness. J Anim Sci 79: 3062 3068 